\title{
"Will I be asked to have sex in the therapy
} room?"

\author{
Susan Quilliam
}

Writer, Broadcaster, Consultant and Trainer, Cambridge, UK

\section{Correspondence to}

Ms Susan Quilliam; susan@susanquilliam.com www.susanquilliam.com

Received 8 August 2012 Accepted 8 August 2012

\section{Background}

In the July 2012 issue of this Journal I reported back on the experiences of psychosexual therapists. ${ }^{1}$ Their voices clearly and movingly described their motivations, their training, their challenges, their magic moments - and their hope for a deeper connection between the medical and therapeutic worlds when it comes to acknowledging and actioning psychosexual support for our patients. In so doing, I hope I helped show Journal readers that such support is a 'Good Idea' and - by inference - that we can confidently refer patients to it.

But hold on. Do patients themselves have any idea what 'psychosexual support' is? In this follow-up article, I explore the questions patients might raise, particularly the one that - whether they admit it or not - is underpinned by sheer terror.

Because, however fully practitioners may be at ease with the concept of professional sex therapy, patients being referred to it will not only feel the normal wariness surrounding the idea of any kind of counselling: "Will I be expected to hit cushions?" (probably not) ... "Will I have to drag up the painful past?" (not always) ... "Will it be confidential?" (yes, absolutely). They will also tap into a whole extra layer of fear based on the natural human need for safety when talking about intensely personal matters.

If we are able to confidently answer patient questions about what sex therapy means and what it involves, that process not only informs but also calms and reassures. Crucially, it also makes it much more likely that patients will proceed down the therapy road and profit as much as possible on their journey.

\section{The basic question}

So what are these patient queries, the ones we are likely to face once we've uttered the "Have you considered therapy?" suggestion? The first and most obvious question is a simple one: "Is it right for me?"

Typically, sex therapy is appropriate if the patient has had their problem for 6 months or longer, if medical solutions have been considered but haven't proved relevant or effective, and if they have already unsuccessfully tried to solve the problem themselves or in conjunction with medical help (Boxes 1 and 2).

What patients - and we practitioners also need to know is that sex therapy may not be the most effective solution if the presenting symptom is down to a tangential problem. Low libido triggered, for example, by a death in the family may best be helped not by sex therapy but bereavement counselling. Erectile dysfunction occurring as a result of an in-crisis marriage won't be patched up by psychosexual support but will need in-depth relationship help. Plus, the therapist themselves will often refer right back to more general or relationship counselling if it seems clear that before they can even start to do good work, clients need to sort out their couple dynamic.

A final point about suitability and effectiveness. Like all counselling, sex therapy will only 'take' if the client is willing. If there's real resistance, it's pointless for the client - and a burden on psychosexual services - to refer on.

\section{The practicality questions}

The next set of patient queries that typically emerges - perhaps because it is the least embarrassing - concerns the practicalities.

"How often will I need to go?" Of course answers vary and anything but an estimate will almost certainly be wildly inaccurate, but most sessions are weekly 
Box 1 For what conditions might sex therapy prove useful?

Sex therapy may benefit any condition that affects a patient's sex life and for which medicine has done all it can. Note, though, that if the problem is down to communication or relationship problems - or any problem that needs general counselling - this needs to be done before sex therapy is possible.

- For her: pain during intercourse, vaginismus, anorgasmia.

- For him: erectile dysfunction, problems controlling ejaculation, anorgasmia.

- For both: loss of desire, sexual identity issues, inhibition, boredom, communication, fear, sexual difficulties caused by ill health, medication or disability.

or fortnightly, up to 50 minutes long, but with added 'at home' work.

"How long will it take?" Patients may expect to see a therapist anything from half a dozen times upwards, though typically won't be facing years of work but rather months. That said, while patient concerns are usually around not spending too much time, some may instead want reassurance that they won't spend too little, that they won't be rushed to a conclusion but can take as long as they need in exploring the issues. (Taking time is also vital because at the heart of successful therapy is relearning - relearning time and time again that sex can be enjoyable.)

"How much will it cost?" Again answers will vary according to local and national resources and to referral choice. Such choice is likely to be four-fold: an in-house, practice-based sexual therapist; a centralised therapy service such as that based at a regional hospital; private psychosexual counsellors; and private counselling organisations or networks, such as (in the UK) Relate or the College of Sexual and Relationship

\section{Box 2 What self-help resources are available?}

There may well be a waiting list for local - even private - psychosexual services. Hence it is useful to suggest that patients explore self-help methods - to resolve their sexual difficulties or to strengthen their relationship - while they are 'on hold'. The following resources may help.

- Sexual Advice Association (http://www.sda.uk.net).

- The Orgasm Answer Guide by Barry R Komisaruk, Beverly Whipple, Sara Nasserzadeh and Carlos Beyer Flores (The Johns Hopkins University Press, November 2009, f11.00) - in-depth advice from a worldwide panel of experts.

- Overcoming Sexual Problems by Vicki Ford (Robinson Publishing, July 2005, f9.99) - information and practical step-by-step advice on resolving sexual problems like vaginismus.

- The Relate Guide to Sex in Loving Relationships by Sarah Litvinoff (Vermilion, March 2001, f8.99) - Relate's guide to sexual fulfillment.

- Sleeping with ED by Victoria Lehmann and Mike Kirby (National Services for Health Improvement, July 2008, f6.00) - guide to coping with erectile dysfunction.
Therapists that offer psychosexual services (Box 3). The first two choices listed are likely to be free or heavily subsidised but have a longer waiting list; the last two choices are likely to be fee-paying but available more quickly. An informed practitioner can help their patient here by guiding them according to the urgency of their need and the resources that are available.

"Who will I see?" Typically one therapist. Occasionally two: one working with each partner then both conferring on a joint treatment plan. As I explained in my article ${ }^{1}$ in the July 2012 issue of the Journal, it's usual for therapists to have originally trained in more general counselling techniques then specialised, or to be medical practitioners who have had extra therapeutic training. Clients attending alone can typically choose to work with a counsellor of their gender of choice.

"Do we both need to go?" If a client is partnered, it's usually preferable for both partners to attend even if the problem seems to affect only one individual; sex itself is such a reflection of relationship state that the therapist needs to see and work with the whole partnership dynamic. That said, if the patient reports that their spouse would need to be dragged kicking and screaming to the therapy room, it's still worthwhile proceeding; a good counsellor can work wonders even with just one client, who can then perhaps transmit details of 'homework tasks' to the absent partner. (And, of course, with tact and time, successful therapy with one partner can be the most powerful persuader to get both partners to attend.)

\section{The activity questions}

"What will happen?" It's usual for the therapist to spend the first session with a client defining the problem and then talking about what they want to achieve. The next step is the taking of a detailed history, typically with each partner on their own.

Thereafter subsequent sessions will typically involve talking - about thoughts, experiences, feelings - that shed light on the problem. Sometimes it's relevant to delve into childhood memories, sometimes the problem is much more based in the here-and-now; often exploration reveals that what seemed like a sexual problem is something deeper, a relationship issue that needs to be resolved. Clients will be expected to talk about their sexuality, but only within

\section{Box 3 Where can one get more information about sex therapy?}

The College of Sex and Relationship Therapy (http://www.cosrt.org.uk)

- The Institute of Psychosexual Medicine (http://www.ipm.org.uk)

- The Porterbrook Clinic (http://www.porterbrookclinic.org.uk)

Relate (http://www.relate.org.uk) 
their own comfort zone; if that is narrow, then the counsellor may well use that very fact as a starting point for work.

"Won't the therapist be shocked?" The patient may need to be reassured that any therapist will, truly, have heard it all before, that they won't judge or criticise and, once again, that everything said in therapy is absolutely confidential.

"What will I be expected to do?" As the therapist and the client(s) start to understand why problems are happening, action plans will start to emerge. Often what's needed is not directly sexual. Clients may be helped to relax, to lower anxiety levels, to gain confidence and self-belief. If lack of knowledge - perhaps about the biology or the mechanics of sex - is at the root cause of their problems, they may be offered additional information. They may be helped to think and feel differently, to rework their beliefs about sexuality, body image, gender roles and what really works in bed.

Particularly when both partners are involved in the therapy, clients may be helped to communicate better about their needs and wants, to encourage sharing of fantasies or, crucially, to develop a common vocabulary that lets them talk more comfortably about sexual issues. Or, with problems that stem back to earlier trauma or sexual abuse, sometimes specific techniques will be used; there is, for example, a growing interest in trauma resolution through eye movement desensitisation (EMDR).

\section{The scary question}

Undoubtedly the most fear-laden question that patients typically have - although, through embarrassment, they may ask the question only in their own minds - is the one that heads up this article: "Will I be asked to have sex in the therapy room?" The answer is a resounding "relax ... don't worry". Granted, particularly where the presenting problem stems from lack of sexual skill, clients will usually be asked to carry out intimate exercises, but with the exception of the rarely-used bodywork approaches I described in my article in the April 2011 issue of this Journal ${ }^{2}$ these will always be at home.

Furthermore, any such exercises will always be only when the patient is ready: no good therapist would ask a client to leap into such activities without full discussion and preparation. Exercises begin from a safe base and build session by session, as clients gain confidence. They take the emphasis off performance and onto 'in the moment' pleasure, because often the original problem began because of pressure to perform. If there's embarrassment, reluctance or resistance, that's also discussed in the therapy sessions and fully resolved before clients are asked to go further.

What kind of exercises will the client be asked to do? At the heart of most sex therapy is sensate focus: gently touching each other at increasing levels of intimacy, through genital stimulation, then masturbation to orgasm and finally - again only when clients are ready - moving on to penetration. Sensate focus not only re-stimulates desire and interest and helps both partners discover what excites the other, but can also be used to address particular issues such as premature ejaculation. (In some cases, such as vaginismus, clients may be introduced to using a dilator, though this will happen later in the therapy and only once the client is completely comfortable with the idea.)

\section{The effectiveness question}

"But will it work?" Of course the bottom-line question is whether sex therapy will be effective, and it's realistic to give patients a very positive response here. Sexual issues are often very susceptible to therapy and the results can be stunning. A study conducted by the British counselling organisation, Relate, in 1999 reported that $93 \%$ of counselling clients felt their sexual relationship improved after using the service. Why? Perhaps because sexual issues can be well defined, perhaps because sex therapy techniques are well developed, or perhaps because often the simple fact of being able to discuss taboo issues - often for the first time - is in itself immensely therapeutic.

That said, it's vital to warn patients in advance that therapy will only be as effective as the effort they put in. Counsellors can't - and won't - provide all the answers and no one is going to wave a magic wand. Part of supporting patients in any medical setting involves managing expectations; guiding them into sex therapy is no exception.

\section{The referral question}

"Where do I find a therapist?" When deciding on what kind of therapy to go for - as mentioned above, the practitioner (National Health Service or private), the regional clinic or the counselling organisation - of course the final call is with the patient. However, the first trawl should, I suggest, be with the health professional, for the more knowledgeable and specific the referral practitioner is about the available options, the more motivated the patient will be to take their suggestions on board.

I truly believe that names, facts, figures and direct experience here count for a great deal when it comes to reassurance, and to lowering patient anxiety. The health practitioner who says "I think there are services available, look them up yourself on the web" will surely have a lower therapy take-up rate (and therefore a lower rate of patient resolution) than the one who accompanies the suggestion of treatment by actively facilitative comments such as "The sex therapy clinic at the hospital is on Wednesdays - it's a very friendly place" or "I've met that counsellor she's very well qualified and lives near you".

To put in the time and energy to gain such a level of first-hand knowledge may seem daunting in these 


\section{Box 4 Do it yourself?}

An alternative to the longer-term therapy described here is for the patient's problem to be addressed within the medical context by their own (therapeutically-trained) doctor or one of their colleagues, often within the same practice.

This clearly has a number of advantages. Issues can be tackled when they arise; patient and doctor have already established a bond of trust; any necessary genital examination may well be more acceptable; and so on. In addition, the fact that solutions can often be offered on the spot may mean the patient is less likely - in the sometimes weeks-long interval before starting therapy - to wobble, or retreat!

Therapy offered as a direct result of a medical consultation is likely to have the same theoretical basis as that described in this article, but could well be more clinically-based, is typically aimed at the individual patient rather than the couple, and often tends towards briefer intervention.

The Institute of Psychosexual Medicine (IPM) offers courses to give trained doctors the qualifications and experience to provide psychodynamically-based therapy. For details of these courses - or for a list of members to whom you could refer your patients - visit the IPM website (http://www.ipm.org.uk)

cash-strapped, time-impoverished days, but it can make all the difference in the world to have this knowledge already at your fingertips when dealing with a therapy-nervous patient. So pop round to the local counselling service provider, or have a coffee with the in-practice therapist; such actions will bear fruit (Box 4).

As will my final suggestion: the offer of a follow-up appointment. Because the question that many patients will never ask, but often want to, is: “...and can I come back to you for further help if sex therapy isn't right for me?" The response "Come back and see me next month and let me know how you're getting on" is the perfect answer to that question, whether asked or not.

\section{Competing interests None.}

Provenance and peer review Commissioned; internally peer reviewed.

\section{References}

1 Quilliam S. Sex therapists make their voices heard. J Fam Plann Reprod Health Care 2012;38:196-198.

2 Quilliam S. Psychosexual bodywork: should we refer our patients, and if so why? J Fam Plann Reprod Health Care 2011;37:241-243. 